\title{
COMPARATIVE ANALYSIS OF FARM ACCOUNTS
}

\author{
E. O. BURNS* \\ Department of Primary Industries, Queensland
}

\begin{abstract}
With the development of farm management extension services in Australia, a need has arisen for an analytical technique which can be handled by extension officers and readily comprehended by farmers. Inter-farm comparison met this need at a similar stage of development in the United States and United Kingdom, and its application to Australian conditions is discussed. Comparative analysis is presented as an integral feature of farm management accounting.
\end{abstract}

Comparative analysis of farm accounts has been described as "poor man's farm management". There have been very few attempts at theoretical justification in Australia, where its reception generally ranges from limited acceptance to round condemnation. At the same time, it is a widely used farm management technique in overseas countries, and it is also being used to an increasing extent in most Australian States. In this paper, I endeavour to show that comparative analysis of farm accounts has an important role to play in farm management work. I also indicate how, in my opinion, the technique should be integrated into a broader plan of farm management extension.

Much of the criticism of comparative analysis has resulted from viewing it as an isolated technique of farm management research and extension. This does not do it justice, as it is not a self-sufficient method in itself. The technique needs to be considered in relation generally to the functions of management and management accounting, and to various historical and institutional factors affecting the development of farm management services. In particular, to gain a balanced perspective, it is necessary to consider:

(i) the historical role of comparative analysis in the development of farm management services;

(ii) the function of management and the orientation of farm management extension; and

(iii) the function of accountancy as a tool of management and the organization of accountancy services.

\section{The Method Outlined}

Comparative analysis is a method of interpreting accounts (which include records of appropriate physical data) in order to provide information which will be of assistance to management in future planning. There will be little argument with the fundamental proposition that the recording of financial and non-financial data can be of assistance in the management of a farming or grazing business. The primary purpose of recording these data should be to serve the ends of management. Accounts can only be interpreted through comparison with other known or assumed data. Comparison may be subjective or objective. In the absence of any

* Grateful acknowledgement is extended to K. O. Campbell for helpful criticism. and suggestions. The opinions expressed, however, are the author's sole responsibility. 
objective basis of comparison, one is forced to rely on notional standards, or pre-conceived ideas of acceptable measures of performance, in relation, for example, to yields and income levels.

Objective bases of comparison fall into two groups-

Internal Comparisons based on:

(a) Past performance, i.e. data in respect to the same property for previous periods; and/or

(b) Budgeted results, i.e. the forecast of planned performance for the period under review.

External Comparisons based on:

(a) Other properties, i.e. average results from a group of similar properties for the same period; and/or

(b) Calculated standards, i.e. standards derived from a study of similar type properties, and assumed to have validity over a longer period than district averages for one year.

Comparative analysis in its usual connotation refers solely to external comparison, principally with other properties, and that is the sense in which the term is used in this paper. The method rests on the assumption that comparison of a number of "efficiency measures", which may be single magnitudes or ratios, for one farm with those of similar type farms (or standards), will reveal comparative weaknesses (and strengths) which provide a starting point for the formulation of a more profitable plan.

\section{Limitations}

Comparative analysis has limitations, and care and skill are required in interpretation. Reference to a single indicator may produce a wrong conclusion, and it is necessary to consider a number in conjunction before obtaining a clear picture of the situation. Engene, after statistically testing data from 1,545 records from the Southeast Minnesota Farm Management Service, covering the 11-year period 1928 through 1938, demonstrated that " "The simple rule that a farmer should improve first the factor in which he is lowest cannot be used safely as a guide in management. A thorough analysis of the nature of all factors and the opportunities for improvement on the individual farm is needed in each case before a positive recommendation can be made to the operator". A seemingly weak measure may be the result of the farm's unique nature within its group. Despite claims to the contrary, this is not a weakness in the technique, as the analyst, in searching for understanding, will discover the reason for the variation and will therefore have a greater appreciation of the farm situation. The method aids understanding of the individual farm. It does not solve problems, although it points the way to their possible solution.

Criticism of the technique generally hinges on this type of limitation, and is valid as far as it goes. The limitations are recognized by proponents of the system. What is not valid is to criticise comparative analysis because it can not do what is never claimed for it. It does not, for example, produce optimum plans. It can not, as a matter of fact, produce

1 Engene, S. A., "New Light on Factor Analysis", J. Farm Econ., Vol. 25, No. 2 (May, 1943), p. 486. 
any plans. It is purely a technique of analysis, which is a separate management function, quite distinct from planning.

Comparative analysis came under some heavy fire in the late 1930's in the United States. One of its severest critics, G. W. Forster, of North Carolina State College, claimed that: ${ }^{2}$

"Of all the methods devised to analyse and present farm management data this method (direct comparison) is the most defective. From most any point of view it can be and has been repeatedly demolished. And yet if we are to believe the reports, this method has been used successfully. It leads one to the observation that a thing does not need to be true in order to be useful,"

This is trenchant criticism but one wonders how useful results could have been derived if in fact the method was so defective.

The clue to this is contained in Forster's following passage-

"In the case of this method, I think what has happened is this: The farmer is conscious that the results presented and the conclusions drawn from these results are not accurate. But nevertheless they are suggestive. To the farmer's mind they suggest certain things which might be done on his farm. It may be that he has not been giving sufficient attention to the size of his farm, to the yields which he is obtaining, or to any other factor which the method of direct comparison features. But that the farmer, except in rare instances, is going to follow the suggestions or conclusions drawn from the results in toto is quite inconceivable. But from such sources he gets ideas which agitate his mind and if he is an alert and intelligent farmer he will modify the suggestion so as to fit the conditions under which he is operating."

This second passage does little to support the earlier condemnation of the method itself. It gives strong support, however, to the statements made earlier that skill is required in interpretation, and that planning is a function separate from analysis.

Anyone using comparative analysis should beware of regarding standards or group averages as ends in themselves. They are not performance targets, but are merely indicators of possible weaknesses to be considered in planning an improved system of management. Comparative analysis of farm accounts is only one of a number of ways of locating weaknesses in management. Certainly there are more refined methods available to the farm management worker, but these are usually much more demanding of time and specialized equipment.

\section{History}

Comparative accounting analysis is a widely used management technique in other countries. Although it apparently originated in American agriculture before the first World War, its practice is by no means confined to primary industry.

I would like to refer briefly to some examples of its use in other countries, not only in agriculture, but also in secondary and tertiary industry. One American firm regularly publishes sets of 14 key ratios for 36 lines of manufacturing industry, 24 lines in wholesaling and 12

${ }^{2}$ Forster, G. W., Discussion ("Theory of the Firm and Farm Management Research'), J. Farm Econ., Vol. 22, No 1 (Feb., 1940) p. 125. 
lines of retail trade. In Western Germany, 2,500 firms in 20 branches of the retail trade were participating in inter-firm comparisons in 1956, and similar work was being done for 17 branches of the wholesale trade. Comparative accounting analysis is also practised on a major scale in the secondary and tertiary industries of France, Holland, the United Kingdom, Norway and Belgium. The European Productivity Agency, an offshoot of the Organization for Economic Co-operation and Development, has been actively promoting inter-firm comparison, as a means of increasing productivity, both nationally and internationally, and a pilot study was conducted with 23 firms in the shoe industries of Italy, France and Spain in $1959 .^{3}$

In agriculture, comparative analysis of farm survey data was developed about 1912 by G. P. Scoville, then County Agent in Chemung County, New York. ${ }^{4}$ Scoville's ideas so impressed the United States Department of Agriculture's Office of Farm Management that arrangements were made for his joint appointment in 1914 as Assistant Extension Professor of Farm Management at Cornell College of Agriculture and farm management demonstration agent for the Department of Agriculture. ${ }^{5}$ Scoville's method, demonstrated at the Fifth Annual Meeting of the American Farm Management Association in 1914, marked the beginning of the use in extension work of the method later to be known as direct comparison.
"Average attributes of 84 farms included in the analysis, and of the 'average (of) 13 better paying farms', were presented; and space was left where the appropriate data for the farm under consideration could be written in . . . A similar type of analysis and comparison was presented for costs and receipts for the farm. The analysis of data from a given farm compared with data from better paying farms was used to suggest alterations which might be introduced to increase the income on the farm concerned."'

Although the comparative technique had now arrived in farm management extension, this was based on survey data, and was not yet comparative analysis of farm accounts. Efforts by extension workers to encourage farm accounting received an impetus from the development of the comparative method and, largely due to the work of Case at Illinois, farm account books had become the main source of data for inter-farm comparison by the early 1920's. A later development in the 1920's was the formation of farm management associations, which provided a detailed business service to participating farmers, based on comparative analysis. ${ }^{7}$ Despite later changes in emphasis in work in the United States, com-

3 Gibson, R. W., "Interfirm Comparisons to Aid Management", Aust. Accountant, Vol. 34, No. 7 (July, 1964), pp. 372-373.

4 Smith, C. B., "The Origin of Farm Economics Extension", J. Farm Econ., Vol. 14, No. 1 (Jan., 1932), p. 20.

5 Burritt, M. C., "Farm Management Extension Work in New York State", American Farm Management Assn,, Proceedings 1914, pp. 62-63, (cited in Taylor, H. C. and A. D., The Story of Agricultural Economics in the United States, 1840 1932, Iowa State University Press, 1952, p. 377).

6 Case, H. C. M. and Williams, D. B., Fifty Years of Farm Management, University of Illinois Press, 1957, p. 83.

7 Ibid., p. 170. 
parative analysis of farm accounts is still used widely in farm management.

Comparative analysis of accounts has been the major farm management tool in Great Britain since the development of farm management advisory services in the early 1950 's, ${ }^{8}$ and a similar situation applies to France, the Netherlands, Sweden, Norway and Germany.

Very little comparative accounting analysis has been attempted in any type of industry in Australia, but its use is increasing. One of the earliest examples in agriculture was afforded by a Western Australian firm of public accountants, who conduct such a service for their clients. Most farm management advisers use the technique, and it is also used to a greater or lesser extent by Departmental extension officers in Victoria, ${ }^{9}$ New South Wales ${ }^{10}$ and South Australia. ${ }^{11}$ The Queensland Department has been running a comparative accounting project on a mail-in basis since July, 1962,12 and the University of New England is engaged in processing data for comparative analysis, in co-operation with farm consultants. ${ }^{13}$

Interest in inter-firm comparison is also growing in manufacturing and retailing industries in Australia. The technique was first mentioned in the accounting literature in Australia in 1962,14 but it has received more prominence recently, largely through the work of $\mathrm{Gibson}^{15}$ and $\mathrm{Hain}^{16}$ of the University of Melbourne. ${ }^{17}$ Studies in comparative analysis have recently been carried out in Australia in respect to hardware retailers, ${ }^{18}$ chemists, food manufacturers and the printing industry. ${ }^{19} \mathrm{~A}$ significant development is the appointment early this year by the Department of Trade and Industry of a full-time consultant to stimulate the interest of Australian industry in inter-firm comparisons. ${ }^{20}$

${ }^{8}$ Murray, Keith A. H., "Agricultural Economics in Retrospect", J. Agric. Econ., Vol. 13, No. 4 (Jan., 1960), p. 380. tion.

${ }^{9}$ Shoobridge, R. G., Department of Agriculture, Victoria. Personal communica-

${ }^{10}$ Druce, P. C., Department of Agriculture, New South Wales. Personal communication. cation.

11 Catt, C. C., Department of Agriculture, South Australia. Personal communi-

12 Moorhouse, W. and O'Neil, A. L., Farm Management Accounting Groups, Report No. 1 South Burnett. Queensland Department of Primary Industries, Brisbane, 1965, p. 1.

13 Anon., Farm Management Service Centre Annual Report 1964-65. University of New England, Armidale, 1965, pp. 1-2, mimeo.

14 Scott, Walter, "The National Obligations of the Cost Accountant", Aust. Accountant, Vol. 33, No. 1 (Jan., 1963), p. 8.

15 For example, Gibson, R. W., op. cit.

16 For example, Hain, B. H. P., "Uniform Accounting for Inter-Firm Comparison", Aust. Accountant, Vol. 34, No. 1 (Jan., 1964), pp. 35-38.

17 See also Meredith, G. G., "Ratio Analysis for Managerial Control", Aust. Accountant, Vol. 34, No. 11 (Nov., 1964), pp. 632-638.

18 Anon., Hardware Retailers: Interfirm Comparison. Business Advisory Centre Pty. Ltd., Melbourne, 1965.

19 Gibson, R. W., University of Melbourne. Personal communication.

20 Anon., "Interfirm Comparisons to be Stimulated", Quest No. 2 (April, 1966), p. 5. 


\section{Management}

These examples from secondary and tertiary industry have been introduced quite deliberately, because $I$ think it is necessary for us to be reminded from time to time that farm management is in fact one aspect of what has come to be called scientific management. There is a tendency in our profession to view farm management solely as a branch of agriculture. This is true in part, but to no greater extent, for example, than management of a colliery is a branch of coalmining. Management is a function quite distinct from technology, and it is an error to believe that farm management is essentially different from management of any other type of industry. This error has been perpetuated not only by agricultural economists and farm management workers, but also by general economists, public accountants, management writers and researchers in industry generally. In fact, the principles of production economics, of management generally and of management accounting are the same for all industry. Unless this fact is recognized, there is the danger of losing the benefits of advances in methodology and theory developed in the general field of management which may have relevance to agriculture. One has only to think of the theory of production economics, of linear programming and production functions, all of which, of course, were developed outside agriculture. In pointing out the dangers of segregation, I am not overlooking, of course, the contributions which agricultural economists have made to general economics.

\section{Developmental Phase}

Comparative analysis should be looked at in a developmental perspective. Although farm management research goes back quite some years in Australia, it must be remembered that serious attempts at farm management extension have only occurred very recently. The farm management consultant or club adviser, and the extension economist of a State Department are in an entirely different situation from the research man with his computer and a handful of case studies. Agricultural economists have stirred up a rapidly growing demand for management assistance at the individual farm level, and it is the general experience of workers actually meeting this demand that the initial data required can best be provided by comparative accounts analysis. This parallels overseas experience. Despite the development of new methodology in the U.S.A., comparative analysis is still one of the techniques most widely used by the farm management extension officer. Long decades of comparative analysis have produced a fund of basic input-output data and information on the economic structure of farm-firms, from which other forms of research have developed.

One should guard against any suggestion that comparative analysis is a technique competitive with more refined methodology. The point is that there is no other suitable technique available for the quick development of a management awareness among farmers and extension officers with no previous management training.

The historical role of comparative accounts analysis in the development of farm management services does not appear to have been recognized by some writers who have referred to an American-Australian school of farm management as opposed to a farm standard school (in 
the United Kingdom). ${ }^{21}$ In the United Kingdom, the accent has been on practical advisory work. Australian research has tended to follow developments in the U.S.A., but whereas in America this has been supplemented and was preceded by a highly organized extension service relying heavily on comparative analysis, it is only in very recent years that we in Australia have attempted to provide farm management extension. Our situation in Australia parallels that described by Blagburn: "... District Officers and farmers press for assistance in farm management, and the economists, deficient in man-power and for the most part lacking electronic computers, have to choose between giving optimum advice to the isolated few and providing something rather more roughand-ready for a larger number." ${ }^{22}$

\section{Farm Management Extension}

Farm management extension should be aimed primarily at making farmers aware of the importance of management, and at improving their decision-making processes. In short, towards making them better businessmen. Much published farm management matter in Australia and overseas makes the tacit assumption that the agricultural economist or farm adviser plays the major role in decision making arising from an interpretation of farm survey or accounting data. The emphasis in farm management extension is on advising individual farmers, using budgeting and sometimes linear programming and other techniques. This emphasis, I feel, is completely incorrect. I am not suggesting that farm management economists should discontinue this work. Far from it. But the fact remains that individual work of this nature can never hope to influence any more than a very small percentage of favoured primary producers. The resources are just not available, and are never likely to be available in sufficient numbers to make a significant impact on the management practices of farmers and graziers generally, even though the position may be relieved to a certain extent when technical extension officers are well trained in farm management.

Not only must farmers be made aware of the necessity for improving their management skills, but farm management economists must pay more attention to developing these skills in the farming community, even if this means a little less attention to individual farmers. An essential requisite to good management in any business is the efficient use of records and accounts. Training of farmers in their use and interpretation might be expected to pay better dividends in the long run than individual assistance in farm planning.

We can distinguish two distinct applications of comparative analysis.

(1) Comparative analysis of data collected from a group of farms as a survey project, often of one year's duration. Data may be collected through a pre-arranged recording system or by interview with a prepared questionnaire.

(2) The use of comparative analysis by the farm manager as an interpretative tool associated with the continuous practice of management accounting.

21 Candler, Wilfred and Sargent, David, "Farm Standards and the Theory of Production Economics", J. Agric. Econ. Vol. 15, No. 2 (1962), pp. 286-288.

22 Blagburn, C. H., "Farm Standards and the Theory of Production-A Rejoinder", ibid., p. 295. 
As a specific project, the first application can produce interesting and valuable information, and may provide some pointers to the association of certain factors with profitability. So far in Australia it has had limited direct application in extension although its use is growing. By providing evidence of the range of performance which is likely to be achieved in practice, it has helped to formulate the subjective standards on which much of our extension necessarily depends.

To my mind, the main aim of projects of this nature should be to demonstrate the advantages of comparative analysis within the wider sphere of farm management accounting. Our farm management extension services should not be content with advising farmers on specific problems, but should aim at developing attitudes and management potential. We should spend less time on moulding management decisions and more time on moulding managers.

\section{Systematic Farm Management Accounting}

An intelligent use of accounts is an inescapable requirement of efficient management. There are three phases in management accounting, whether in primary industry or any other type of industry. These are (i) recording and preparation of statements; (ii) interpretation of statements; and (iii) planning and budgeting. These three phases repeat in a continuous cycle.

The use of comparative analysis in the interpretation phase constitutes the second application of the technique mentioned above. It provides indicators to directions in which the farm organization and practices may be improved. The feasibility of any changes under consideration can then be tested with budgets. After the plan has been decided, its progress is controlled by comparison of progressive recorded figures with budgeted figures until the phase is again reached when the annual statement is subjected to external comparison. Certainly there are problems in the practical implementation of this type of system on a widespread scale, but I believe we in Australia have good opportunities for overcoming these. All we need, as I see it, is, firstly, a recognition of the value of farm management accounting, and secondly, willingness to cooperate on the part of all who are concerned with farm management. This includes agricultural economists and extension officers of State Departments, those in farm management workshops and service centres at Universities, farm management consultants and club advisers, and practising accountants. Schapper has also drawn attention to this need, and has indicated the favourable conditions existing in Western Australia for the development of this type of co-operation. ${ }^{23}$

The prime requirement is for farmers to accept the necessity for adding managerial skills to their technical skills. All of the professional classes and institutions I have mentioned must share the task of bringing this about, and of instructing farmers in the simpler techniques of accounts analysis and budgeting. Co-operation between all these sections is imperative if farm management is to make any really significant contribution to Australian agriculture. It would be unrealistic to attempt to impose a rigid pattern on the form of co-operation. The farm manager himself must be free to choose the type of advice he considers approp-

23 Schapper, H. P., "Needed Developments in Farm Accounting", Farm Policy, Vol. 4, No. 1 (June 1964), pp. 26-27. 
riate. This will depend to a large extent on what is available to him.

We already have in Australia examples of farmers receiving management advice from:

(a) farm management consultants on their own;

(b) farm management club advisers on their own;

(c) farm management consultants and advisers in conjunction with public accountants;

(d) departmental economists in collaboration with extension officers;

(e) departmental economists, extension officers and public accountants in collaboration;

(f) departmental economists on their own;

(g) public accountants on their own; and

(h) various combinations of the above in collaboration with universities.

Comparative analysis of farm accounts is a widely used tool in all these situations. The main difficulty is the dearth of comparative data, and it is here that either State Departments of Agriculture, or Universities as independent institutions, can play an important role. It would be highly desirable for one institution in each State to act as a collecting agency for farm accounting data, and to prepare annual averages and standards on a district and industry basis for feed-back to all users. This would be a big undertaking, requiring quite a deal of organization, and would require a high level of co-operation among all parties, especially public accountants. It would also require, of course, a standard terminology and method of accounts presentation. We have already made some real progress in Queensland along these lines. Recently published is a report by a joint committee on farm management accounting appointed by the Queensland Department of Primary Industries and representing the accountancy institutes, the University of Queensland and the Queensland Department. ${ }^{24}$

Some time has been spent on issues which might appear to be somewhat broader than the subject of this paper. It is necessary, however, for an assessment of comparative analysis that we should appreciate its possibilities in management control.

\section{Present Practice of Comparative Analysis}

Certain problems arise in the practical application of comparative analysis of farm accounts in our present stage of development. As practised to some extent in most Australian States, this is a technique partly of fact-finding, and partly of extension. Typically, annual financial data and efficiency factors are calculated for a relatively small number of farmers with similar enterprises and in the same geographical region. Each farmer's situation is then compared generally with averages of all farms and averages of best farms, and sometimes with each farm in the group.

From the practical farm management worker's point of view, these projects have five aspects: collection of data; selection of co-operators; selection of significant parameters for comparison; interpretation of

24 Accounting and Planning for Farm Management. Qld. Dept. of Primary Industries, Brisbane, 1966, pp. 158. 
individual accounts; and follow-up work with the farmer. Let us look at each of these aspects separately.

\section{Collection of Data}

I will deal with this first because the method of collecting data determines to some extent the method of selecting co-operators. Basically, data can be collected in two ways-from past records, or from records kept as part of the project. Past records usually mean taxation returns supplemented by the farmer's memory. Using this type of data has some advantages, and many disadvantages. It is easy to collect, involving in each case one farm interview and one visit to a tax agent, and results can be obtained quickly. The disadvantages are well known. Depreciation is unreliable and usually needs to be recalculated, valuation of livestock is unrealistic, capital expenditure must be removed from the accounts, and many individual items (both of income and expenditure) are aggregated. Furthermore, there is no uniformity in the aggregation.

If data are collected through a record-keeping project, the records can be so designed to produce whatever data are required for analysis in a uniform manner. The disadvantage is that if analysis is being made on an annual basis, the interest of co-operators has to be maintained for a year. The usual way of achieving this is to arrange for regular collection of data by personal visit to co-operators. This is time-consuming, and in practice often results in the investigator actually writing up the records on each visit, whether or not this was originally planned. An alternative is for co-operators to mail-in their records, either on an annual or more frequent basis. A monthly basis allows a certain amount of interim processing to be performed, but its most important advantage is that it enables a check to be made on the continuing interest of the farmers. Follow-up checks can be made when returns are delayed, and interest possibly revived before it is too late. A fairly substantial proportion of wastage is inevitable with a mail-in system.

We have a mail-in farm management accounting system in Queensland. Farmers are recruited voluntarily at meetings called specially for the purpose of explaining the scheme. During the year they mail in monthly particulars of their receipts and payments, in single column cash sheets. Dissection is made in the Department. In addition, they supply a beginning and closing inventory, and monthly particulars on a prepared sheet on cropping, livestock and labour changes. Normally their annual results are discussed with an economist once a year, but we depend otherwise on correspondence for clearing up problems and maintaining interest. Our experience after three years of this scheme is that 25 per cent of those signifying their intention to join the scheme do not even start, although they have been provided with the record books. Out of those who do start, 75 per cent finish one year, 50 per cent are still with us after two years, and 33 per cent finish three years.

\section{Selection of Co-operators}

Where information is to be collected on a single farm-interview basis, the usual conditions for any farm survey apply. The sample may be selected at random or purposively, depending on the nature of the enquiry. The number of potential cases for observation is much reduced where records are to be kept. The limiting factor here is willingness and 
ability. Even with voluntary co-operators, as I have shown, a substantial number fail to complete their undertaking. Results from record keeping projects can not be expected to reflect average district results. They are biased towards those willing and able to keep records. These would tend to be above-average farmers. However, comparative analysis is still a valid tool in these circumstances for indicating possible directions in which changes might prove profitable.

\section{Selection of Significant Parameters for Comparison}

A large number of measures in absolute, percentage or ratio form have been used in inter-farm comparisons. The value of the method depends largely on the appropriateness of the measures selected. Selection should be logical and designed to give an appreciation of as many aspects of the business as the records are capable of revealing. Hopkins and Heady ${ }^{25}$ suggest the selection of measures under the following headings-Scale of Operations, Livestock Efficiency, Crop Efficiency, Labour Efficiency, Machinery Economy, Cost Ratios, Capital Ratios, Income Ratios and Enterprise Selection. Yang ${ }^{26}$ lists a number of key measures of farm income, and sets out factors affecting farm income under the following headings - Size of Farm Business, Rates of Production, Choice and Combination of Enterprises, Intensity of Cultivation, Labour Efficiency, Input-Output Ratios, and Capital Efficiency.

Although classifications may differ in detail, variations in farm profitability may be attributed basically to size of business, rates of production, efficiency in use of resources, selection and combination of enterprises, and prices. Selection of appropriate measures within these categories depends on the type of enterprise and the availability of data. There is almost no limit to the number of possible ratios and measures which can be calculated. The aim in selection of measures should be to bring under observation as many as possible of the different aspects of the farm business.

The selection of significant parameters needs an acquaintance with local conditions. There is no virtue in multiplying a number of measures, all of which refer to the same basic relationship. There is also no virtue in ascertaining relationships which can not conceivably influence farm efficiency. The selection of measures to be used is the key problem in comparative accounts analysis. In 1950, the U.S. North-Central Farm Management Extension Committee reported: ${ }^{27}$

"The long list of measures used in annual farm business reports suggests the need for further study of such measures and their role in farm record analysis. There is need to clarify further the minimum requirements for satisfactory analysis of the farm business. There is need to bring together information on the methods by which various measures are calculated and the inherent characteristics affecting their

25 Hopkins, John A. and Heady, Earl O., Farm Records and Accounting, 4th edn., Iowa State University Press, 1955, pp. 190-204.

26 Yang, W. Y., Methods of Farm Management Investigations, F.A.O. Agricultural Development. Paper No. 80, Rome, reud, edn. 1965, pp. 56-68.

27 Anon., "Farm Record Analysis in the Extension Programmes of the NorthCentral States", Report of the North-Central Farm Management Extension Committee, Farm Foundation, Chicago, 1950, p. 25, mimeo, (cited by Case, H. C. M. and Williams, D. B., op. cit.). 
use as measures of performance and in the analysis of significant relationships.

"There is need to further develop methods of analysis that will provide more significant standards of comparison for individual farms and greater validity of conclusions regarding cause and effect relationships. The final goal of studies aimed at these needs should be the development in each state of the most useful measures and methods of analysis consistent with objectives and with available resources of manpower and funds. A thorough study in this field should be made as a co-operative effort of farm management research and extension workers."

Although written in the U.S. 15 years ago, this quotation neatly sums up our present position in Australia.

\section{Interpretation of Individual Accounts}

The first step in interpretation is to establish the comparative profitability of the property, by comparing gross income, total expenses and net income. The second step is to look at the comparative size of the property. Size is often measured by area, but land is not the only resource used in farming, and it may be more appropriate to compare the labour force, the number of livestock units, or the value of invested capital. These two steps provide the initial general picture of financial performance and farm resources. It is only against this background that efficiency measures can be interpreted in any meaningful manner.

There is no mechanical procedure for carrying out comparative analysis. A practitioner soon works out the process which suits him best. Most have a number of key ratios to which they first turn. These include gross income per acre, yield per acre or per unit of livestock, net income (or operating profit) per acre, and rate of return on assets employed. Some people find it useful at the outset to have some indication as to whether the farm's main problem is on the income side or the cost side - whether output needs to be increased or costs reduced. A useful indication can be given by considering two ratios in conjunction. These are: (a) Capital Turnover Ratio, i.e. Gross Income/Capital Value; and (b) Returns/Expenses Ratio, i.e. Gross Income/Farm Expenses. Low capital turnover, with either a high or low Returns/Expenses ratio, suggests that output should be expanded. High capital turnover with a low Returns/Expenses ratio, on the other hand, suggests that costs should be reduced. Consideration of these two ratios provides a guide as to the direction the subsequent analysis should take. In general, one finds that the basic solution to most individual farm problems lies in efforts to increase gross income rather than to reduce costs. Gross income is a function both of production and price and both aspects should be examined. In most cases, it will probably be found that the physical level of output is more important than the level of prices obtained.

\section{Follow-Up Work with Farmer}

The whole purpose of comparative analysis is to provide guideposts for more profitable planning in the future. The method has little value if it does not initiate any planning activity. Comparative analysis in itself can not produce a detailed plan for more profitable farming. Sometimes it can point in a broad direction to be followed. On other occasions it may 
indicate certain aspects of the farm structure which need examination. Ideally, every farmer participant in a comparative accounting project should subsequently have plans prepared and tested by budgeting. This is being done in Australia to a certain extent by farm management consultants and club advisers and State officers. Independent farm management workers probably do this to a greater extent than Departmental people, but this is time consuming work and I suspect that club advisers and consultants find that they have insufficient time to do as much as they would like in this direction, just as do their Departmental colleagues.

While it is easy to be purely theoretical in the farm management field, we must face the fact that there are now quite a few people, compared with only a few years ago, who are actually trying to meet the demands of individual farmers for farm management assistance. Some of us are in State Departments of Agriculture, some in Universities, some in private practice, engaged either independently or in group work. And in many if not most cases, I should say, the demand is much too great to provide what we know to be optimal service from the individual farmer's point of view.

It might be asked if detailed plans and budgetary analysis are always necessary. In many cases they are not. From a practical extension point of view, many farmers are looking firstly for very general guidance, and are perfectly happy to have pointed out that they are below average perhaps in certain technical aspects. This gives them something to work on. This is useful extension, even if it is not very spectacular. At the same time, the farmer is learning to rely on his records, and hence to be a better manager. It is a fact that the majority of farmers, because they have no basis of comparison, have very little idea of their relative position in their industry or district in respect to their financial position or their technical efficiency. We have all probably met farmers operating at very low levels of efficiency, technically and financially, who nevertheless believe that they are typical and that everyone else in the industry is in the same situation. Comparative analysis is a very effective way of producing the awareness which is the first step towards improvement. The advantages of comparative analysis are not confined to those taking part in a specific recording programme. It is of assistance to any farmer provided he arranges for his accounts to be prepared in a uniform manner.

\section{Co-operative Effort}

I have stressed previously that the main function of farm management extension is to produce better farm managers, and that inter-firm comparison is a very useful tool of management control. I have set up as an aim, the development of a level of sophistication in management which is far in advance of the level at which we are accustomed to dealing.

Applied farm management is a very practical, down-to-earth discipline, and we must keep our feet on the ground. I believe, however, that we must have a long-term aim. We might ask ourselves "What is our attitude to farm management? Do we want to make farmers dependent on us all their lives? Do we want to gain the applause of other farm management workers by neat pieces of research? Or do we seriously want to improve the level of business management on our farms?" If the last is the case, I suggest that this can best be achieved by co-operative 
effort on the part of all who are concerned in the problem. Any permanent improvement in managerial efficiency can only be achieved by placing much reliance on accounts and other records oriented to management decision making. In my view, comparative analysis is an indispensable feature of farm management accounting.

It is inevitable that in these circumstances, public accountants will be called on to an increasing extent to provide more comprehensive accounting services than have been usual in the past. Some farm management workers, while accepting this as inevitable, have some reservations about its desirability, particularly where it concerns accountants who generally have little knowledge of farming operations. From my own experience with a number of Queensland accountants who are becoming active in the field, I think these fears might be exaggerated. Management in manufacturing relies on both the financial controller and the engineer. Similarly in primary production, the management accountant and the technical adviser have their respective spheres.

Comparative analysis as so far developed in Australia is concerned mainly with the farm's operational results. This is logical as comparative analysis has been developed by farm management economists who are primarily concerned with this aspect. If the accountancy profession had taken it up, probably greater attention would have been paid, for example, to capital stability and financial policy. These are also important aspects of business management with which the average accountant is much more at home than the average farm management worker. As the practice of management accounting grows, so can we expect more sophisticated accounting analysis. This will result in more informed decision making, and is a very good reason for close co-operation on our part with the accountancy profession. We have only touched the surface of management accounting analysis in Australia. 